\title{
Don't be a Deadbeat Dad: Non-Custodial Fathers, Stereotypes, and Family
}

\author{
Kiana Sillence ${ }^{1}$
}

\begin{abstract}
The objective of this paper is to explore how gender stereotypes influence social structures which creates barriers for non-custodial fathers (NCF) and to identify possible solutions to challenge societal prejudice. The findings suggested that gender stereotypes shape NCF's perception of fatherhood, the mother's opinion of NCFs, the proceedings during a custody battle, and the type of social services provided to NCFs. These act as barriers that negatively affect NCF-child relationships, which are further diminished by non-cooperative mother-father relationships. Surprisingly, stepfamilies were found to improve NCF-child relationships. Remote fathering was found to be detrimental to children's development that can result in poor socioemotional adjustment, increased externalized problems, diminished abilities to form strong bonds with friends, and feeling lonely. It was also found that absent fathers increased the risk of their children developing behavioural problems, engaging in criminal behaviour, and experience poverty. Based on qualitative data, possible solutions outreach programs created through community collaboration, that promote education, empathy and respect. For more problematic NCF visitation, perhaps a version of the Israeli visitation center could be used. In sum, these conceptual solutions can challenge gender stereotypes and social prejudice which benefits NCFs and family as a social institution.
\end{abstract}

\section{Introduction}

\footnotetext{
${ }^{1}$ MacEwan University
} 
It is common knowledge that gender inequality between males and females exist in most cultures around the world, where male dominance is supported by inherently patriarchal social structures (Kimmel et al., 2017, p. 1). Individuals are socialized in their respective gender roles from day one, based on idealistic concepts of sex-based abilities Each culture constructs unique gender stereotypes, but it is typically based on dualistic ideals, despite the spectrum of gender expression and identity within each culture (Kimmel et al., 2017, p. 2, 100). Furthermore, gender stereotypes enforce an expectation for individuals to act out the appropriate gender performances according to the meaning attached to their biological sex (Kimmel et al., 2017, p. 2).

Realistically speaking, when considering the way people live in society on a daily basis, there is no such thing as perfect duality between genders, nor are such stereotypes realistic or achievable. After all, there are far more similarities between genders than there are differences (Kimmel et al., 2017, p. 12). On the basis of these differences, however, gender can be socially constructed and interwoven into society, informing social institutions such as the economy, the education system, or the family. The gender stereotype for men, for example, is often based on hegemonic masculinity, which embodies traits deemed superior to femininity and subordinate masculinities (Kimmel et al., 2017, p. 8). The family, for instance, is a gendered institution which reinforces a parental dichotomy, where mothers provide childcare and are innately compassionate and empathic, and fathers are required to fulfil the role of provider and protector. (Roberts et al., 2014, p. 7). The gender stereotype for fathers, in particular, is consistent with hegemonic masculine norms that portray the ideal man as having control over his emotions and maintaining economic success (Roberts et al., 2014, p. 7-8, 396). A deviation from these gender norms can be socially condemned as effeminate behaviour or subordinate forms of masculinity (Roberts et al., 2014, p. 7-8, 396).

In accordance with hegemonic masculine norms, NCFs would be considered a subordinate form of masculinity, yet he would still be expected to provide for the family through child support. Put another way, a NCF may lose his family through divorce or separation, lose custody over his child, and is subsequently left to struggle economically to support himself and to pay child support. Since this is the reality for most NCFs, they are part of the male population that is subject to harmful gender stereotypes. This is no surprise, considering the history that plays a part in shaping current gender stereotypes of fatherhood today. The present paper will explore what gender stereotypes influence social structures, how this creates barriers for NCFs and family as a social institution, and what solutions can challenge these gendered social norms.

\section{Deadbeat Dad: An Introduction to Non-custodial Fathers}

When a NCF loses custody over his children, he is removed from the family dynamic because he no longer has a say in how his child is raised. Furthermore, NCFs are seen as an abnormal father figure that doesn't fit into the social expectations for what a family should look like. NCF's are often vilified as inadequate parents, despite the reality of their experiences that are 
contrary to the outdated stereotypes they are beholden to. To better understand this, it is important to assess how NCFs became known as deadbeat dads in the 1980s, and how this still shapes gender stereotypes today.

In the US, during the 1980's, President Reagan helped influence the reestablishment of family values, which is essentially the religious-based epitome of the gender stereotypes discussed in the introduction (Krämer, 2016, p. 225). That is, mothers are bound to provide childcare and nurturance, where fathers have a superior role as the breadwinner and head of the house. Not only do these family values reproduce gender stereotypes, but Reagan's government shifted some of the financial responsibility of the state to the individual (Krämer, 2016, p. 224-225). This compounded the pressure on fathers to uphold their ability to financially support their family, as society experienced a decrease in social services to help them if they failed economically (Krämer, 2016, p. 226). This was considered synonymous with failing to uphold the moral standard of a good father by neglecting his duties. Both of these were aspects that influenced the creation of the label, deadbeat dads, given to NCF's who didn't pay child support (Krämer, 2016, p. 226).

In short, deadbeat dads were considered to be men who had failed to meet the gender expectation for fathering. Instead, these indebted NCFs were criminalized, oppressed, and shamed if they could not uphold child support payments. As a result, a NCF's manhood would be considered to have sunken to the level of subordinate male, as he would not embody the hegemonic masculine traits necessary to be socially accepted (Kimmel et al., 2017, p. 8). Even though these seem to be the opinions of the past, these ideas have had a residual effect on the general demeanour towards, and expectations for, NCFs. In other words, the Reagan-era generated ideas that would influence gender stereotypes that have been resistant to time and the remnants remain. Today, NCFs are still considered abnormal parents, yet their gender role as the family provider is still expected (White et al., 2001, p. 156).

Regardless of these restricting expectations, NCFs still wish to provide a nurturing environment and emotional support for their children (Roberts et al., 2014, p. 5, 7). In saying this, Gold \& Adeyemi (2013) discussed a 21st-century concept of fatherhood, in which a father is expected to be the breadwinner, while also providing a nurturing and supportive environment for their child (Gold et al., 2013, p. 99). However, this can lead to an increase in responsibility and pressure by taking on the expectation of two gender roles (Gold et al., 2013, p. 99). In sum, these gender stereotypes are problematic because they reinforce a rigid paternal dichotomy that is normalized in society and reproduced in everyday life. When in fact, we do not need specific roles to ensure families function properly since there are so many family forms that gender stereotypes only prove to be restricting. In other words, these gender stereotypes paint a broad brush across all fathers, inaccurately representing fatherhood and establishing unachievable expectations. To address these issues, this paper will first address how gendered stereotypes affect NCFs.

\section{Beyond the Stereotype: Non-Custodial Father's Experiences}

NCF's feelings and opinions about fathering directly contradict the stereotypes by revealing an emotional and nurturing parental figure who desires to be a good father (Rogers et al., 2019 , p. 2). Each father may have a parenting style that mimics or rejects their own fathers 
parenting techniques based on their experiences growing up (Rogers et al., 2019, p. 2). Regardless, these ideas of fatherhood can completely change when faced with family isolation, societal barriers, and the humiliation NCF's experience when they lose custody of their child. It begs the question, how does a NCF continue to be a parent when they have limited involvement in their child's daily life and legally no input in how they are raised? They may feel as though they have sacrificed a part of their identity as a father, and now have to navigate a confusing and ambiguous landscape (Gold et al., 2013, p. 101). In fact, it was found that $80 \%$ of NCF's felt disempowered when they were unable to have input in their child's life (Gold et al., 2013, p. 101). Nevertheless, many NCFs still felt proud as a father and maintained the belief and desire to fulfill their paternal role (Lehr et al., 2001, p. 337). However, it can be frustrating to have gone through a custody battle (Lehr et al., 2001, p. 373). That is, since mothers are typically assumed to be the primary caregiver with innate nurturing abilities, compared to the fathers that may feel that they have to defend their parenting abilities every step of the way (Lehr et al., 2001, p. 373). These are some of the many unreasonable expectations working against NCF's, which are only made worse by the social barriers NCFs experience.

\section{A Product of Gender Stereotypes: Barriers Faced by NCFs}

In the process of becoming a NCF, part of that individual's identity as a father and a husband seem to slip away when they become legally isolated from their family (Gold et al., 2013, p. 102). This can lead to the first barrier NCFs face, which is the internalization of gender stereotypes. After all, the restricted access and minimal involvement in their children's daily lives limits NCFs role in providing payment for child support. Therefore, NCFs are legally beholden to these gendered expectations, otherwise, his moral standing as a good father may be reduced that of a deadbeat dad (Krämer, 2016, p. 232). This leaves some NCF's believing that they are a bad father, even though no one has told them directly, but it is the process of becoming a NCF that can make them feel that way (Lehr et al., 2001, p. 380). In short, the social construct of gender stereotypes reinforces parenting norms that directly affects the fathers who are trying to become more than what society expects them to be. To make matters worse, the pressure to conform to these gender stereotypes are reinforced by mothers and the judicial system, embedded in social services, and made worse by economic demands.

\section{Gatekeepers: Maintaining the Distance}

One of the most reported barrier by NCFs is how difficult it is to come to terms with the distance from their family, especially if it is maintained by the mother who can act as a gatekeeper between the NCF and their children (Roberts et al., 2014, p. 2; Gold et al., 2013, p. 101-102; Lehr et al., 2001, p. 374, 377-378; Kissman, 2001, p. 139; Finzi-Dottan et al., 2016 p. 339; Buchbinder, 2015, p. 162). Ultimately, NCF's are deemed a lesser parent rather than a co-parent by the judicial system, and this can be reproduced based on the mothers' perspective (Gold et al., 2013, p. 101). Subsequently, the mother may claim last-minute unavailability before a scheduled visit, or contact is cut off between the NCF and his child if there is poor cooperation between the two parents 
(Roberts et al., 2014, p. 2; Gold et al., 2013, p. 101; Lehr et al., 2001, p. 374). Furthermore, fathers may even avoid picking their child up for a visit if the mothers' confrontation about child support becomes overwhelming (Lehr et al., 2001, p. 374). This level of isolation and unpredictability may leave many fathers feeling disempowered (Gold et al., 2013, p. 101). After all, NCFs are unable to fulfill their parenting role in this type of situation.

\section{The Judicial System: Legal Barriers}

NCFs are further affected by gender stereotypes that may influence the decisions of the judicial system that delegates custody and determines child support. It is true, however, that for the protection of certain families or to help mothers battling gender income inequality, a father might lose custody and be required to pay child support. In this case, custody and child support are essential to the well-being of a family. That being said, given the research, many NCF's have an underlying drive and ability to be a good, nurturing, supportive father and their loss of custody is influenced by outdated beliefs about a father's ability to parent (Roberts et al., 2014, p. 7; Roberts et al., 2019 p. 46; Gold et al., 2013, p. 99; Lehr et al., 2001, p. 377-378; Finzi-Dottan et al., 2016 p. 337-339; Buchbinder, 2015, p. 161-163). That being said, it is hard to imagine why a father who has the capacity to be a good parent would want to go through a custody battle where the mother may be favoured by the court. It may be in the hope that they will gain custody since the barriers that exist as a non-residential father also exist for NCFs. In other words, a custody battle might be worth the risk since some non-residential fathers are faced with similar barriers to a NCF. In fact, on the road to becoming a NCF, a non-residential father may experience the same distance from the family and restrictions on child visitation implemented by the mother (Roberts et al., 2014, p. 2-3). Especially so if the parents do not have a cooperative relationship, which can motivate the fathers' desire for a custody battle (Roberts et al., 2014, p. 6).

However, this may not be the best solution when considering mothers win $86 \%$ of custody battles in the US (Gold et al., 2013, p. 100). Furthermore, the father is likely to struggle to find a lawyer without a significant amount of money and he may have to endure animosity and restricted access to his children during the custody battle (Lehr et al., 2001, p. 375). Not to mention, he may face a courtroom that believes in the inherent capacity of a mother to care for children unless she is violent or uses drugs and alcohol (Lehr et al., 2001, p. 375). Therefore, the process will likely give custody to the mother, and degrade the father's role as a parent in the process. That is, a NCF is intrinsically bound to his provider role when he becomes legally obligated to provide child support, but restricted from parenting (Gold et al., 2013, p. 101).

Krämer et al. (2016) described this situation perfectly by mentioning a program that presented a racialized NCF attending court to explain that he was three thousand dollars behind on child support payments because the mother had restricted visitation with his child (p. 234). In response, the mother is surprised and ensures that she would never do such a thing. Regardless of the actual situation, in the ' 80 s the mother would be considered the victim by default if the father did not uphold his gender role as the provider (Krämer, 2016, p. 234). Although this is not the case for every custody battle, all trials should be unbiased and objective. Yet, it is hard to do so when the decisions of family law are influenced by gender stereotypes that reinforce the socially accepted gender division of parental abilities and expectations. 


\section{Economic Barriers}

In addition to the expectation that men will be economically successful, this pressure will double if they are a father, and triple if they become an NCF that has to pay child support. Subsequently, after losing a battle for custody, NCFs are left in legal limbo where they are unable to be a parent of their child due to restrictions and expectations for fulfilling the economic obligation of child support (Gold et al., 2013, p. 100). However, this is not always possible for every individual to fulfill. In fact, there are 1.7 million fathers in the US and some are NCFs who have economical struggles (Roberts et al., 2014, p. 2-3). This reality contradicts the gender stereotype of fatherhood, as not everyone can obtain enough income and power in society to fulfill the expectations hegemonic masculinity requires. One might ask, how does this pressure affect young fathers that may not have the education or job experience to obtain a job to fulfill these payments? Furthermore, what if the father is paying for university tuition to obtain a degree to get a well-paying job, but they need to choose between child support or education payments? Even these individuals are not free of the gender stereotypes expected of all fathers, and NCFs alike, without consideration of their struggles and circumstances.

In response to this, a feminist may rightly point out that men have more privilege in western patriarchies compared to women. However, not every man is economically successful and powerful, therefore, some men are vulnerable to the social barriers created by gender stereotypes. In fact, earning enough money is thought to be one of the main obstacles for NCFs, and is often the only way to guarantee the mother will allow the NCF to see their child (Kissman et al., 2001, p. 136). This does not leave room for marginalized fathers, such as disadvantaged or even homeless NCFs. For example, it has been found that disadvantaged NCFs feel they have major issues, such as the threat of incarceration or finding a job, which keeps them from focusing on the needs of their extraneous children. (Kissman et al., 2001, p. 142). There are also homeless NCFs that makeup part of the $68 \%$ of homeless people that are fathers. In this case, the expectation to uphold the family provider role still plagues them despite their more urgent need for emotional, physical and economical help (Rogers et al., 2019, p. 39-40). Indeed, there are social services out there to help the homeless, disadvantaged and even the average NCFs (Rogers et al., 2019, p. 39-41; Kissman, 2001, p. 140-141; Buchbinder, 2015, p. 155). However, it seems many of these services have expectations of their own that are informed by gender stereotypes and are sometimes unconsciously reproduced in the services they provide to NCF's.

\section{Social Services: Providing Paradoxes}

Even though the gender stereotypes within social services may be hard to imagine, the real implications are apparent in the negative effects they have on NCFs. In one study, Kissman (2001) assessed the effectiveness of an already existing intervention program for disadvantaged NCF's. It was found that there needed to be many adjustments and additions to the program to meet the needs of these fathers, which only became apparent when researchers connected directly with them rather than basing services off assumptions (p. 144). This is an example of social services having the best intentions, but without careful consideration, it is easy to miss what the fathers need. This can be influenced by gendered assumptions that limit the services to educational and employment 
assistance (Kissman, 2001, p. 140-141). By extension, homeless NCF's (HNCF) are also plagued by unrealistic economic expectations because most social services only serve women and children (Rogers et al., 2019, p. 40). However, these faults do not go unnoticed by everyone, as many of the front-line service provider employees see the effects it has on homeless fathers.

Based on what social service employees had seen and heard, it was found that they recognized the failings within certain service provider organizations. Employees reported paradoxes within the services provided to homeless NCF's, which left HNCFs feeling hopeless, stigmatized, and shameful (Rogers, 2014, p. 43) In short, social services are attempting to help NCF's, but subconsciously they are influenced by normalized gender expectations of fathers which is manifested in the limited services they provide for men. Specifically, social services were found to use generic case files that lack interpersonal connection (Rogers et al., 2019, p. 44). Furthermore, the case files may be embedded with gendered assumptions for what all NCF's need help with which often revolves around income and employment (Rogers et al., 2019, p. 44). Even the average $\mathrm{NCF}$, in Israel for instance, reported feeling that child visitation centers provided social service but they were controlled like a jail and the employees looked down on them as threatening or violent (Buchbinder, 2015, p. 159, 160, 165). Therefore, whether the NCF is from Israel, or homeless in the US, both of them face a general stigma and prejudice in the very place they should be receiving help and compassion. In sum, social services of all types require reconsideration of how they treat individuals since this can create detrimental barriers to NCF's as they attempt to become a better father by getting the help they need.

\section{Larger Implications: Affecting the Family Dynamic}

Not only do these stereotypes create social barriers that affect the micro-level dynamic of the family between father, mother, child and stepfamily, but they also affect the family as a social institution. At the heart of it, the mother-father relationship is critical to the success or failure of the family unit after the father becomes NCF. Ideally, the father and mother should have a cooperative relationship with mutual respect, by setting aside issues and animosity around divorce or remarriage to focus on the children (Gold et al., 2013, p.100-101; Roberts et al., 2014, p. 2). Unfortunately, this is not always the case, the relationship can be aggressive and hostile where the mother restricts the father from seeing the child if the NCF is behind on child support payments. Also, the fathers may be concerned about the mother confronting him for child support that he may neglect other parental duties. (Kissman, 2001, p. 140). Here, NCF's are caught between the desire to be a better father, by fostering the father-child relationship, and the relationship with the mother who controls child visitation. In short, if child support is not paid, it can reduce child visitation and, by paying child support, this may increase child visitation. In both situations, money is the most important aspect of this equation between the NCF and his children.

Given this environment of tension, one would think that the addition of stepfamily members would only make the family dynamic more complicated. This is sometimes the case, especially if the NCF and stepfather are unable to put their differences aside or downplay any competition (Gold et al., 2013, p. 102). Furthermore, if the child only remembers living with their stepfamily and not with the NCF, this may negatively affect the NCF-child relationship (Aquilino, 
2006, p. 943; White et al., 2001, p. 164). However, contrary to popular belief, NCF's remarriage was shown to benefit the family dynamic, because this was associated with an increase of fatherchild contact (Aquilino, 2006, p. 943; White et al., 2001, p. 164). Despite these positively correlated findings, it is the case that both NCFs and step-fathers are beholden to the same provider stereotype that plagues most men, which only adds to complicate the dual paternal roles as they clash and overlap in their efforts to be a father (Gold et al., 2013, p. 102).

Thus far, it is clear that NCF faces many barriers that may prevent them from fulfilling their role, and these effects also have an impact on the lives of their children. For instance, due to the physical distance and restriction for visitation, this can result in the breakdown of the fatherchild relationship as they age because of that lack of presence (Aquilino, 2006, p. 943). Aquilino et al. (2006) found that more than half of the children in the sample $(\mathrm{N}=359)$ had seen their father once a month, where 30\% said they had not seen their father in more than three months, leaving most of them feeling depressed and unhappy. (p. 936). Furthermore, children often get caught inbetween parents aggression, frustration, and power struggle which can diminish the NCF-child relationships and increased likelihood of their child developing poor coping methods such as externalizing and internalizing problems (Gold et al., 2013, p. 100-101; White et al., 2001, p. 157158). Additionally, this negatively affects socioemotional adjustment that was shown to occur when children did not have a significant relationship with their NCF (Gold et al., 2013, p. 158). These experiences are only made worse if their father is disadvantaged or homeless, as they may not receive the proper social support and often have compounding inequalities that are the focus of their attention, restricting them from there parental duties (Kissman, 2001, p. 144). This can result in an absent father, which increased the risk of their children developing behavioural problems, engaging in criminal behaviour, and experience poverty. (Kissman, 2001, p. 144; Rogers et al., 2019 p. 46). Therefore, it is shown by many studies that there are multidimensional negative effects on a child's life that stem from the barriers NCF's face.

In fact, there is a specific time for instability in the family that can cause long-lasting ramifications on children's development. It was found that stress for a child can first start with a change in family structure that then triggers a domino effect. The child can be affected by the change in employment and income, to parental expectations that may disrupt the life and relationships that the child has (Cavanagh et al., 2008, p. 1266). Cavanagh \& Huston (2008) subsequently found that the earlier this instability occurs, typically between birth and kindergarten, the worse the effects on the child would be when they reach fourth grade (Cavanagh et al., 2008, p. 1266). The earlier the instability, such as the father losing custody and separating from the family, the less they are able to navigate relationships, form strong bonds with their friends, and the lonelier they felt (Cavanagh et al., 2008, p. 1266). The more instability experienced, the worse their social adjustment and the higher their externalized behaviours were, among other issues (Cavanagh et al., 2008, p. 1265). In short, this study is an example of the extent to which the harmful effects of stereotypes can reach. Therefore, if NCF are prevented from having a relationship with their child, it may be the case that it is not strengthening the family as an institution, but impeding the functioning of alternative family forms instead. 


\section{Possible Solutions}

Considering the intersecting implications that negatively affect NCFs and their families that have been discussed in the present paper, it is clear that a change is needed. Firstly, the existing social services should treat NCF's with more respect by acknowledging their emotions and ability to be a competent nurturing father (Lehr et al., 2001, p. 379; Gold et al., 2013 p. 102). Perhaps, by providing online resources to educate and try to normalize different family forms, the stigma around support and information about navigating step-family families and different forms of paternity will decrease. (Lehr et al., 2001, p. 379). In addition to these general changes, there are specific programs that may be more effective than others.

For instance, outreach programs can be effective for all families even though this paper has only discussed them in terms of HNCFs and disadvantaged fathers (Rogers et al., 2019 p. 45-46; Lehr et al., 2001, p. 379). In fact, by pooling their services through community collaboration, social service providers can create programs that reach out to communities using formal or informal techniques, to educate families of the services available (Rogers et al., 2019, p. 45-46; Lehr et al., 2001, p. 379; Kissman, 2001, p. 144). Community collaboration allows for multiple services to work together and share resources to better support individuals like NCF. For example, providing support during court proceedings in a custody battle, discussing parenting strategies and child development education, and creating support groups with other parents (Lehr et al., 2001, p. 379; Kissman, 2001, p. 137). These solutions and adjustments are a way to challenge the gendered stereotypes and norms that create strife within the family dynamic through education and providing the proper services that meet the needs of fathers and families. Additionally, adopting some services provided to disadvantaged NCFs could also be beneficial. These programs could provide services to new parents, NCF's, stepfathers, and families in general that revolve around ideas of parenthood and responsibility. Furthermore, the program could include learning coping methods for complex emotions, job and employment services, and improving nurturing and parenting practices that encourage collaboration (Kissman, 2001, p. 137, 144). These are elements of social services that address the legitimate needs of fathers and families articulated by the families themselves, rather than simply assuming what they need.

Lastly, perhaps a version of Israeli visitation centers could be used for difficult cases involving NCFs. Some fathers found it very useful in facilitating a safe space with activities that fathers and their children can engage in (Buchbinder, 2006, p. 161-162). This is particularly important if the mother and father have a violent relationship so that the child is not caught in the crossfire of anger and disputes over child support (Buchbinder, 2006, p. 161-162). More importantly, this may be a space for recovering addicts or mentally unwell fathers to meet with their child so that it is in a controlled and safe space. It can be a space for fathers to accept help and work through their feelings of weakness or ambiguity as NCF (Buchbinder, 2006, p. 165). While this may stigmatize non-custodial fathering, it may also be something that is commonly used in more complicated situations to allow both children and fathers to develop a relationship where otherwise there may not be an opportunity. 


\section{Conclusion}

This paper explored how gender stereotypes influence social structures and create barriers for NCFs and family as a social institution. Furthermore, possible solutions were discussed that may help rectify prejudice within society. By exploring the research on NCFs, it is apparent that what we believe to be true as a society, is not necessarily the whole truth. Most of what is know about NCFs are misconceptions based on Reagan-era concepts of deadbeat dads and toxic forms of hegemonic masculinity that influence the social institutions within society. NCFs may internalize these stereotypes which restrict their longing to cross the gender divide by nurturing and providing emotional support for their child. These gendered expectations affect the way a father views themselves as a paternal figure, and it also shapes the mother's expectations, the judicial system's decisions, and it limits the social services provided to NCFs. In fact, the judicial system may initially believe in the mother's innate abilities to parent, as she is assumed to be the primary caregiver, where fathers are not. Therefore, the gender divide widens when a NCFs' role as the provider is legally determined in a custody battle, and his desire to be a parent is confiscated. This stereotypical provider role is especially detrimental to disadvantaged and homeless NCFs because they face further barriers due to the paradoxes within the social services available for men.

These gender stereotypes don't just affect the NCFs, but also individual family dynamics at a micro level, and the social institution of family at the macro level. Firstly, the father-mother relationship that lacks cooperation and mutual respect proved to diminish the father-child relationship. As a result, children are left feeling depressed and they may develop poor coping strategies such as externalizing problems and poor socioemotional adjustment. Furthermore, instability in the family around preschool-aged children causes children to have difficulty navigating relationships and developing strong bonds with friends. During these early stages, father involvement and supportive parenting practices are linked to increased cognitive and language abilities in children, fewer behavioural problems in school, and less likely to engage in delinquent behaviour when they reach adolescence. (Raeburn, 2015, p. 147, 150-151). The reality of the importance and influence of a father in the family and the development of children is evidence that what society believes to be true is not what is known to be true based on research.

Given these findings, one would think that society would have adopted these facts to replace paternal gender stereotypes. However, fighting against a system that is stuck in the past is not easy and may seem hopeless. A key solution is community collaboration between social services in an effort to understand NCFs, and meet the multidimensional needs that NCFs have. Specifically, outreach programs can educate and provide support for NCFs and communities in general. This may prove to create a deeper understanding of what families need and reduce the stigma around alternative family forms. After all, the family form has has changed over time and this is evidence that there is no one way to have a family. In conclusion, NCFs involvement in their child's life should be considered essential to the family dynamic and the barriers they face prove to impact the whole family. Society can benefit from the normalization of alternative forms of fatherhood by encouraging them to share their experiences when conducting NCF research and creating solutions to help break the cycle of negative barriers imposed by gender stereotypes. In other words, a renewed perspective on fatherhood can prove to challenge social prejudice through education and support. 


\section{References}

Aquilino, W. S. (2006). The Noncustodial Father? Child Relationship from Adolescence into Young Adulthood. Journal of Marriage and Family, 68(4), 929-946. doi:10.1111/j.17413737.2006.00305.x

Buchbinder, E. (2015). Fathers Under Scrutiny: Non-Residential Fathers' Perception of Visitation Centers. Journal of Divorce \& Remarriage, 56(2), 155-169. doi:10.1080/10502556.2014.959108

Cavanagh, S. E., \& Huston, A. C. (2008). The Timing of Family Instability and Children's Social Development. Journal of Marriage and Family, 70(5), 1258-1270. doi:10.1111/j.17413737.2008.00564.x

Finzi-Dottan, R., \& Cohen, O. (2016). Fatherhood: Comparison Between Divorced Custodial Fathers, Married Fathers, and Divorced Non-Custodial Fathers in Israel. Marriage \& Family Review, 53(4), 320-346. doi:10.1080/01494929.2016.1158220

Gold, J. M., \& Adeyemi, O. (2013). Stepfathers and Noncustodial Fathers: Two Men, One Role. The Family Journal: Counselling and Therapy for Couples and Families, 21(1), 99-103. doi:10.1177/1066480712456829

Gunnoe, M. L., \& Hetherington, E. M. (2004). Stepchildren's Perceptions of Noncustodial Mothers and Noncustodial Fathers: Differences in Socioemotional Involvement and Associations with Adolescent Adjustment Problems. Journal of Family

Psychology, 18(4), 555-563. doi:10.1037/0893-3200.18.4.555

Kimmel, M. S., \& Holler, J. Z. (2017). The Gendered Society, Fifth Edition. Ontario, Canada: Oxford University Press.

Kissman, K. (2001). Interventions to Strengthen Noncustodial Father Involvement in the Lives of Their Children. Journal of Divorce \& Remarriage, 35(1), 135-146. doi:10.1300/j087v35n01_08

Krämer, F. (2016). Hazards of Being a Male Breadwinner: Deadbeat Dads in the United States of the 1980s. Historical Social Research, 41(1), 233-239. doi:10.12759/hsr.41.2016.1.223239

Lehr, R., \& Macmillan, P. (2001). The Psychological and Emotional Impact of Divorce: The Noncustodial Fathers Perspective. Families in Society: The Journal of Contemporary Social Services, 82(4), 373-382. doi:10.1606/1044-3894.186

Raeburn, P. (2015). Do fathers matter?: what science is telling us about the parent we've overlooked. New York: Scientific American/Farrar, Straus and Giroux.

Roberts, D., Coakley, T. M., Washington, T. J., \& Kelley, A. (2014). Fathers' Perspectives on Supports and Barriers That Affect Their Fatherhood Role. SAGE Open, 4(1), 215824401452181. doi:10.1177/2158244014521818

Rogers, T. N., \& Rogers, C. R. (2019). Social Services Professionals Views of Barriers to Supporting Homeless Noncustodial Fathers. Family Relations, 68(1), 39-50. doi:10.1111/fare. 12345

White, L., \& Gilbreth, J. G. (2001). When Children Have Two Fathers: Effects of Relationships with Stepfathers and Noncustodial Fathers on Adolescent Outcomes. Journal of Marriage and Family, 63(1), 155-167. doi:10.1111/j.1741-3737.2001.00155.x 